\title{
Titanium Surface Roughing Treatments contribute to Higher Interaction with Salivary Proteins MG2 and Lactoferrin
}

\author{
${ }^{1}$ Yuri Wanderley Cavalcanti, ${ }^{2}$ Rodrigo Villamarim Soares, ${ }^{3}$ Marina Araújo Leite Assis \\ ${ }^{4}$ Elton Gonçalves Zenóbio, ${ }^{5}$ Francisco Mauro da Silva Girundi
}

\begin{abstract}
Some surface treatments performed on titanium can alter the composition of salivary pellicle formed on this abiotic surface. Such treatments modify the titanium's surface properties and can promote higher adsorption of proteins, which allow better integration of titanium to the biotic system.
\end{abstract}

Purpose: This study aimed to evaluate the interactions between salivary proteins and titanium disks with different surface treatments.

Materials and methods: Machined titanium disks $(n=48)$ were divided into four experimental groups $(n=12)$, according to their surface treatments: surface polishing (SP); acid etching (A); spot-blasting plus acid etching (SB-A); spot-blasting followed by acid etching and nano-functionalization (SB-A-NF). Titanium surfaces were characterized by surface roughness and scanning electron microscopy (SEM). Specimens were incubated with human saliva extracted from submandibular and sublingual glands. Total salivary protein adsorbed to titanium was quantified and samples were submitted to western blotting for mucin glycoprotein 2 (MG2) and lactoferrin identification.

Results: Surface roughness was statistically higher for SB-A and SB-A-NF groups. Scanning electron microscopy images confirmed that titanium surface treatments increased surface roughness with higher number of porous and scratches for SB-A and SB-A-NF groups. Total protein adsorption was significantly higher for SB-A and SB-A-NF groups $(p<0.05)$, which also presented higher interactions with MG2 and lactoferrin proteins.

Conclusion: The roughing of titanium surface by spot-blasting plus acid etching treatments contribute to higher interaction with salivary proteins, such as MG2 and lactoferrin.

Clinical significance: Titanium surface roughing increases the interactions of the substratum with salivary proteins, which can influence the integration of dental implants and their components to the oral environment. However, those

\footnotetext{
${ }^{1,5}$ Department of Prosthodontics and Periodontology Piracicaba Dental School, Piracicaba, São Paulo, Brazil

${ }^{2-4}$ Department of Dentistry, PUC Minas, Belo Horizonte, Minas Gerais, Brazil
}

Corresponding Author: Yuri Wanderley Cavalcanti, PhD Student, Department of Prosthodontics and Periodontology Piracicaba Dental School, Piracicaba, São Paulo, Brazil Phone: 551983909920, e-mail: yuri.wanderley@yahoo.com.br treatments should be used carefully intraorally, avoiding increase biofilm formation.

Keyword: Dental implants, Salivary pellicle, Salivary proteins, Peptides.

How to cite this article: Cavalcanti YW, Soares RV, Assis MAL, Zenóbio EG, da Silva Girundi FM. Titanium Surface Roughing Treatments contribute to Higher Interaction with Salivary Proteins MG2 and Lactoferrin. J Contemp Dent Pract 2015;16(2):141-146.

\section{Source of support: Nil}

\section{Conflict of interest: None}

\section{INTRODUCTION}

Commercially pure titanium and its alloys are the materials of choice for implants, abutments and healing caps. To achieve the wound healing at the material-tissue interface immediately after titanium insertion, the presence of proteins from blood and saliva is of utmost importance to obtaining a favorable performance of the biomaterial. ${ }^{1}$ Therefore, the quantity and quality of the adsorption of distinct molecules on the titanium surface are also important to the clinical success of implants.

Among the relevant molecules presents in saliva, mucin glycoprotein 2 (MG2) takes part in the acquired pellicle formed over oral surfaces, preventing the peeling of soft tissues and aiding in chewing, swallowing, and speaking. ${ }^{2-4}$ MG2 interacts with diverse oral microorganisms displaying fungicidal and bactericidal activities. ${ }^{3-5}$ Besides that, lactoferrin also plays an important role in acquired pellicle because it binds to ferric ions and presents relevant antimicrobial and anti-inflammatory activities. ${ }^{6-8}$ Thus, MG2 and lactoferrin consist in significant components of the innate immune system present in the oral environment, which interacts with implant surfaces. ${ }^{7,9}$

When exposed to oral cavity, titanium surfaces become covered by a protein-rich pellicle, which is usually comprised of salivary amylase, proline-rich proteins, secretory immunoglobulin-A, mucin glycoproteins, albumin and fribronectin..$^{10-12}$ The composition of salivary pellicle formed over titanium surfaces is dependent of the 
saliva and serum influxes. ${ }^{11,12}$ Furthermore, the surface properties of the biomaterial affect the composition of the pellicle formed on its surfaces. ${ }^{11,12}$ These aspects may influence the adherence of microorganisms, ${ }^{10,12}$ as well as the attachment of human cells to the titanium surface. ${ }^{13-15}$

In order to modulate the acquired pellicle formation and, consequently, interactions with biotic system, many studies have sought to identify the best titanium surface characteristics for implants and trans-mucosal abutments. ${ }^{13-17}$ These characteristics should be compatible with lower biofilm accumulation and high biocompatibility. ${ }^{11,12,18-21}$ Some of these treatments can contribute to hemi-desmosomes attachment and/or bone cells proliferation, which can favor the integration of implants and their components to the oral environment. ${ }^{13-17}$

For this, spot blasting and acid etching treatments have been proposed, in order to influence the surface roughness and surface free energy, which are considered important factors that influence acquired pellicle composition and, consequently, the interaction with microbial and human cells. ${ }^{13-21}$

Different types of dental implants differ in terms of their composition (commercial pure or alloys), geometric design and surface treatment. However, the interactions that occur between salivary proteins and different titanium surfaces are not well explored. Considering this, it is important to know the interactions between salivary proteins and implants surface, as well as to determine specific components that may be present in pellicle formed over these implants. Thus, the aim of this study was to evaluate the interactions between salivary proteins and titanium disks with four different types of surface treatments.

\section{MATERIALS AND METHODS}

\section{Experimental Design}

It was performed an experimental in vitro study with blind analysis. Machined disks ( $\mathrm{n}=48$ ) made of commercial pure titanium type II were divided into four experimental groups $(n=12)$, defined according to their surface treatments: surface polishing (SP); acid etching (A); spot-blasting plus acid etching (SB-A); spot-blasting followed by acid etching and nano-functionalization (SBA-NF). Titanium surfaces were characterized concerning their surface roughness and micromorphology [scanning electron microscopy (SEM)]. Specimens were incubated with human saliva extracted from submandibular and sublingual glands and total salivary proteins adsorbed to titanium disks were quantified. Later, samples were submitted to western blotting for MG2 and lactoferrin identification.

\section{Titanium Disks}

Forty-eight sterile machined commercially pure (Type II) titanium disks (Neodent_-ILAPEO; Curitiba, Paraná, Brazil) with same dimensions and weight (diameter: $4.0 \mathrm{~mm}$, height: $1.0 \mathrm{~mm}$, weight: $100 \mathrm{mg}$ ) were divided into four experimental groups $(\mathrm{n}=12)$, defined according to their surface treatments: surface polishing (SP); acid etching treatment through acid subtraction process (A); spot-blasting with abrasive particles plus acid subtraction process (SB-A); and spot-blasting with abrasive particles, followed by acid subtraction process, and nanofunctionalization (SB-A-NF). The surface treatments evaluated in present study were created and developed by the manufacturer, for dental implants coating and surface functionalization. Figure 1 shows the macroscopic view of a representative disk from each group.

\section{Surface Roughness Evaluation}

The surface roughness was evaluated using a profilometer (Surfcorder SE1700; Kosaka Laboratory Ltd, Tokyo, Japan), with $0.01 \mathrm{~mm}$ resolution, calibrated at $0.8 \mathrm{~mm}$ sample length, $3.2 \mathrm{~mm}$ measurement pathway, and $0.5 \mathrm{~mm} / \mathrm{s}$ speed. Three measurements were done for each specimen ( $n=6$, for each group), and the average was calculated. Data from surface roughness was analyzed by one-way ANOVA and Tukey test, at $5 \%$ of significance.

\section{Surface Characterization by SEM}

To characterize the titanium disks surfaces micromorphology, specimens ( $n=3$, for each group) were prepared for SEM (JSM 5600LV, JEOL, Tokyo, Japan) evaluation, in high vacuum mode at $15 \mathrm{kV}$, with $1000 \times$ magnification.

\section{Saliva Collection and Total Protein Quantification}

Stimulated human saliva from submandibular and sublingual glands was collected from health volunteers $(n=3)$, which were asked to avoid the ingestion of food or drink for at least 2 hours preceding saliva collection. This study was previously approved by the Research and Ethics Committee of Pontifical Catholic University of Minas Gerais (Protocol No. 213/2008) due the collection of stimulated human whole saliva for acquired pellicle formation.

Salivary stimulation was performed with citric acid and the saliva was collected with an individualized collector. Saliva from submandibular and sublingual glands was selected due to the higher secretion of mucin and lactoferrin by these glands. Samples were poured in sterile $15 \mathrm{ml}$ tubes, which were maintained on ice during the collection period. Saliva samples were polled and 

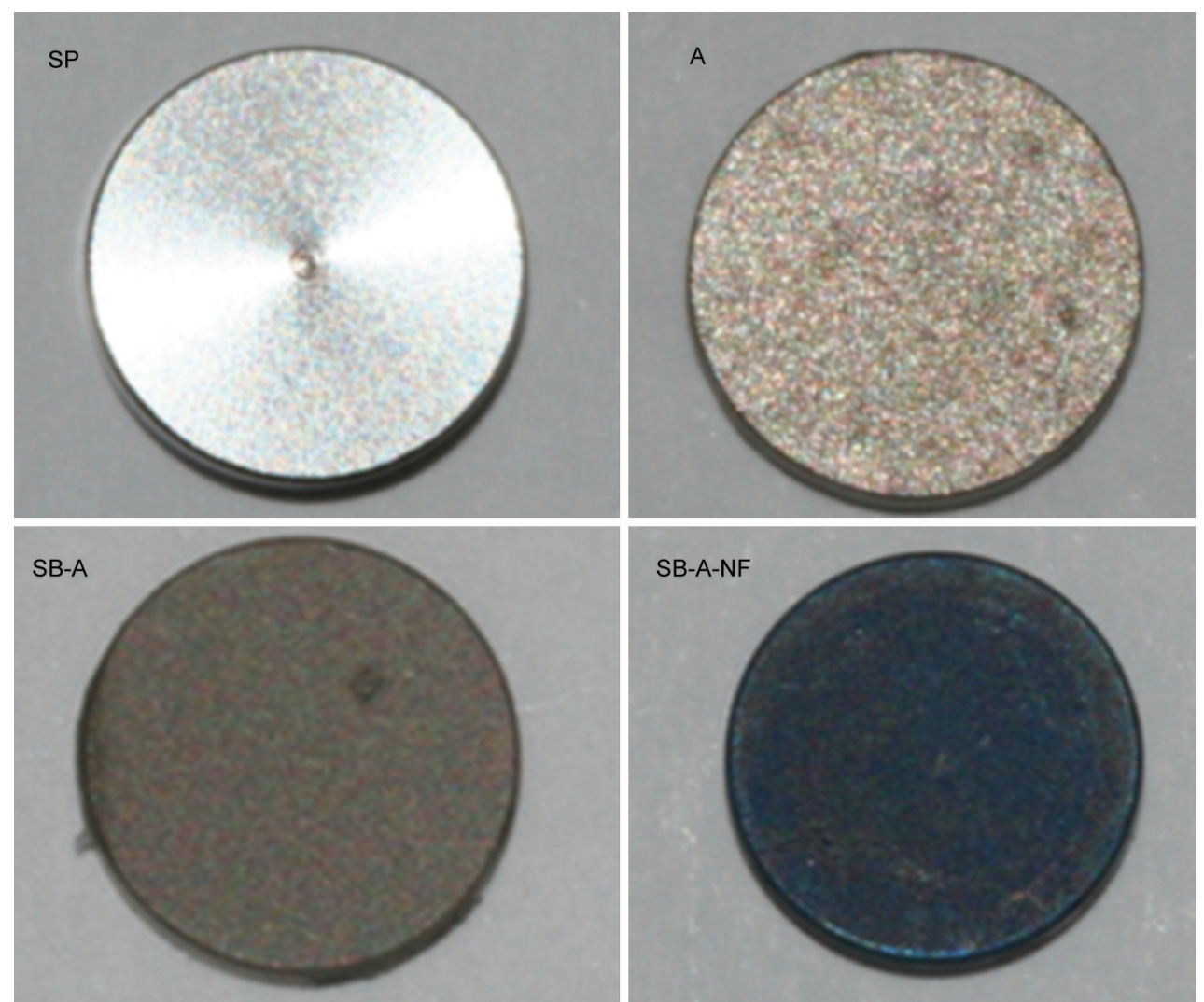

Fig. 1: Macroscopic view of representative titanium disks according to surface treatments performed: surface polishing (SP); acid etching (A); spot-blasting and acid etching (SB-A); spot-blasting and acid etching followed by nano-functionalization (SB-A-NF)

clarified by centrifugation (6,000 g, 10 minutes). Aliquots were used in subsequent experiments.

The total protein quantification was determined by a spectrophotometer at $215 \eta \mathrm{m}$ (A215 method), by means of a specific absorption coefficient of 15 , for a $1 \mathrm{mg} / \mathrm{ml}$ albumin solution in a $1.5 \mathrm{ml}$ cuvette. ${ }^{22}$ Total protein concentration from polled saliva was used to predict the concentration of proteins absorbed or not to titanium disks.

\section{Adsorption of Salivary Proteins to Titanium Disks}

The protocol used in this study was reported previously. ${ }^{23}$ Titanium disks were incubated (3 times, 5 minutes each) in $10 \mathrm{mM}$ Tris- $\mathrm{HCl}$ (pH 7.5) containing $154 \mathrm{mM} \mathrm{NaCl}$ (TBS). Each disk was incubated with 0.5 $\mathrm{ml}$ of saliva samples in microtubes $(1.5 \mathrm{ml})$ and shaken at room temperature (RT) for 2 hours. The tubes were centrifuged (7,500 g, 3 minutes), and the supernatant was removed and separated for electrophoresis. Disks were then washed twice in $1 \mathrm{ml}$ of TBS. The acquired pellicle was removed from the titanium surfaces by incubating the disks at $100^{\circ} \mathrm{C}$ for 5 minute with $300 \mu$ of a solution containing $0.064 \mathrm{mM}$ Tris- $\mathrm{HCl}, 2 \% \mathrm{SDS}, 10 \%$ glycerol, and 10\% 2-mercaptoethanol ( $\mathrm{pH}$ 6.8). Total proteins present in supernatant or acquired pellicle were quantified by a spectrophotometer at $215 \mathrm{\eta m}$ (A 215 method). The values were normalized according to concentration of proteins in polled saliva. Data from total protein concentration from each group was analyzed by one-way ANOVA and Tukey test, at $5 \%$ of significance.

\section{Electrophoresis of Salivary Proteins Adsorbed or not to Titanium Disks}

Salivary supernatant samples, containing proteins that did not interact with the titanium disks, and acquired pellicle from specimens were lyophilized. These samples were submitted to electrophoresis in separation gels $(7.5 \%$ SDS-PAGE), which were prepared with $0.375 \mathrm{M}$ Tris- $\mathrm{HCl}$ buffer (pH 8.8) containing $0.1 \%$ SDS, $50 \mu \mathrm{l}$ of $100 \mathrm{mg} / \mathrm{ml}$ ammonium persulphate, $2.5 \mathrm{ml}$ of bis-acrylamide solution (1:37.5) at $30 \%$ in water, and $5 \mu \mathrm{l}$ of TEMED, in a final volume of $10 \mathrm{ml}$. After polymerization of the separation gels, the superior gels were prepared in a $0.125 \mathrm{M}$ Tris- $\mathrm{HCl}$ buffer ( $\mathrm{pH} 6.8$ ) containing $0.1 \%$ SDS, $1.67 \mathrm{ml}$ of $30 \%$ bisacrylamide, $50 \mu \mathrm{l}$ of $100 \mathrm{mg} / \mathrm{ml}$ ammonium persulphate, and $10 \mu \mathrm{l}$ of TEMED, in a final volume of $10 \mathrm{ml}$. Electrophoresis was performed in a $0.025 \mathrm{M}$ Tris- $\mathrm{HCl}$ buffer containing $0.18 \mathrm{M}$ glycine $(\mathrm{pH} 8.3)$ and $1 \%$ SDS for approximately 2 hours at RT with a current of $80 \mathrm{~V}$.

\section{Western Blot Assay}

Salivary proteins were transferred by electrophoresis to nitrocellulose membranes (Protran and PerkinElmer; 
Table 1: Surface roughness $(\mu \mathrm{m})$ of titanium disks according to surface treatment groups

\begin{tabular}{ll}
\hline Titanium disks & Surface roughness $(\mu m)$ \\
\hline SP & $0.15 \pm 0.09^{\mathrm{a}}$ \\
A & $0.31 \pm 0.12^{\mathrm{a}}$ \\
SB-A & $0.74 \pm 0.17^{\mathrm{b}}$ \\
SB-A-NF & $0.85 \pm 0.24^{\mathrm{b}}$ \\
\hline
\end{tabular}

Different superscript letters show statistical significant differences (ANOVA and Tukey tests)

Waltham, MA, USA). Transferences were performed in a $0.025 \mathrm{M}$ Tris- $\mathrm{HCl}$ buffer $(\mathrm{pH} 8.3)$ containing $0.19 \mathrm{M}$ glycine and $20 \%$ methanol, with $100 \mathrm{~V}$ for 1 hour at RT. Immobilized salivary proteins were incubated in a 10 $\mathrm{mM}$ Tris- $\mathrm{HCl}$ buffer (pH 7.5) containing $150 \mathrm{mM} \mathrm{NaCl}$ and $0.05 \%$ Tween 20 (TBST) for 5 minutes. Samples were blocked with TBST containing 5\% milk at RT for 1 hour. The membranes were washed in TBST ( 3 times, 10 minutes each) and incubated with primary antibodies (produced in rabbits) directed against MG2 and to lactoferrin, diluted 1:1000 in TBST, containing 1\% milk, at RT for 1 hour.

Membranes were washed in TBST ( 3 times, 10 minutes each) and incubated with alkaline phosphatase-conjugated secondary antibodies (produced in goat-antelopes; Promega, Madison, WI, USA), diluted to 1:7500 in TBST containing 1\% milk, at RT for 1 hour. Membranes were washed in TBST ( 3 times, 10 minutes each) and incubated with BCIP and NBT according to manufacturer instructions (Promega). Electrophoretic band were analyzed qualitatively by means of intensity revealed on gels.

\section{RESULTS}

The surface roughness of SB-A and SB-A-NF groups was significantly higher compared to other groups $(\mathrm{p}<$ 0.05) (Table 1). SEM images (Fig. 2) confirmed that titanium surface treatments increased surface roughness, especially for SB-A and SB-A-NF groups, in which were observed the presence of various porous. Acid-etching treatment (A group) provoked less irregularity on titanium surfaces when compared to spot-blasting treatments (SB-A and SB-A-NF groups). The nano-functionalization did not alter significantly the aspect of titanium surface submitted to spot-blasting and acid etching treatments.

Total protein concentration in polled saliva was 2,45 $\mathrm{mg} / \mathrm{ml}$ and the adsorption of salivary proteins to titanium surfaces (Table 2) was significantly higher for SB-A and SB-A-NF groups $(\mathrm{p}<0.05)$. Besides that, SB-A and SB-A-NF presented the greatest interaction with MG2 (Fig. 3; lanes 6 and 8) and with lactoferrin (Fig. 4; lanes 6 and 8). On the other hand, surface polished (SP) disks presented the least interaction with MG2 (Fig. 3; lane 2) and lactoferrin (Fig. 4; lane 2).
Table 2: Total salivary protein concentration ( $\mathrm{mg} / 100 \mathrm{ml}$ ) adsorbed titanium disks according to surface treatment groups

\begin{tabular}{ll}
\hline Titanium disks & Protein concentration $(d p)$ \\
\hline SP & $17.0 \pm 6.06^{\mathrm{a}}$ \\
A & $25.1 \pm 4.10^{\mathrm{a}}$ \\
SB-A & $42.3 \pm 7.07^{\mathrm{b}}$ \\
SB-A-NF & $48.1 \pm 8.04^{\mathrm{b}}$ \\
\hline
\end{tabular}

Different superscript letters show statistical significant differences (ANOVA and Tukey tests)

\section{DISCUSSION}

According to the results of this study, the titanium roughing obtained from surface treatments improved the interaction between the commercially pure titanium and salivary proteins. The irregularity found on treated titanium surfaces probably aided to a major protein adsorption in these sites. This phenomenon is important because surface treatments can improve the integration of titanium to the biotic system, allowing the biding of important proteins and the attachment of human cells to this abiotic surface. ${ }^{13-17}$

Besides the higher absorption of total salivary proteins, spot-blasted and acid etched specimens also presented higher interaction with MG2 and lactoferrin proteins. Although these proteins were detected on all evaluated surfaces, greater interaction was seen for SB-A and SB-A-NF groups, showing that surface modification also contributed to selective protein absorption. Given that MG2 and lactoferrin can agglutinate microbial species and act as fungicidal and bactericidal agent, ${ }^{2-9}$ their presence in titanium's salivary coatings can contribute for a healthy healing process after titanium placement.

Treatments such acid etching, spot-blasting and nanofunctionalization aim to improve surface roughness and to modify the surface free energy. ${ }^{15-17}$ This modification of titanium implants surfaces have been reported as beneficial to human cell attachment and to the success of osseointegration. ${ }^{13-17}$ However, care must be taken considering the microbial proliferation over titanium surfaces. Although MG2 and lactoferrin may present antimicrobial activity, these proteins cannot sufficiently eliminate the microbial colonization.

Nevertheless the surface treatments evaluated in present study are commonly used on the titanium implant threads, ${ }^{13-16}$ these sites are eventually exposed to saliva and to intra-oral bacteria. Therefore, infection must be controlled during the healing process of implants placement. This may allow human cells attachment and the effectively integration of titanium to the biotic system. ${ }^{13,14}$

Healing caps, abutments and prosthetic components are mainly machined and have their surface polished. This can contribute to lower biofilm accumulation; 

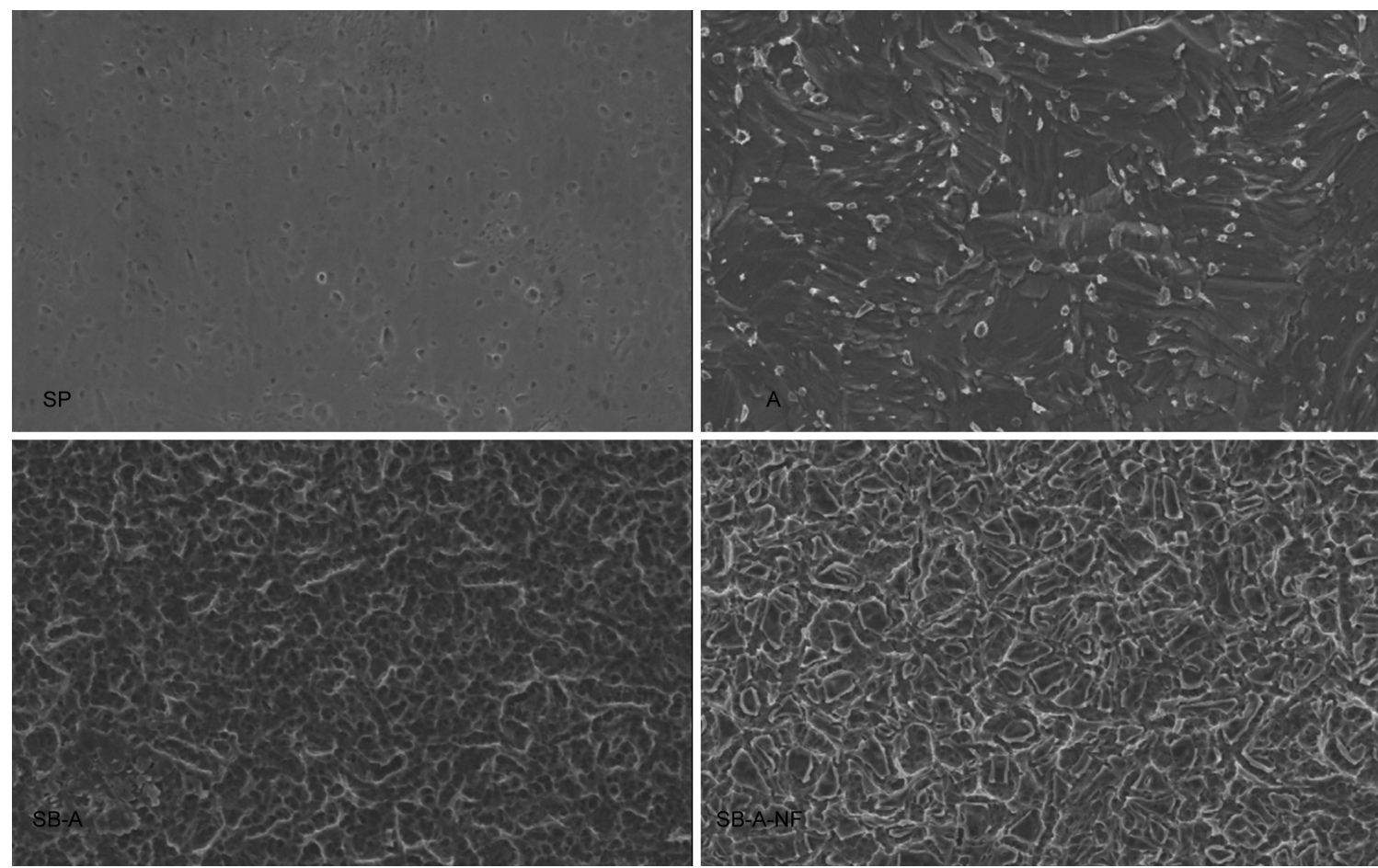

Fig. 2: Scanning electron microscope images of titanium discs according to surface treatments performed: surface polishing (SP); acid etching (A); spot-blasting and acid etching (SB-A); spot-blasting and acid etching followed by nano-functionalization (SB-A-NF)

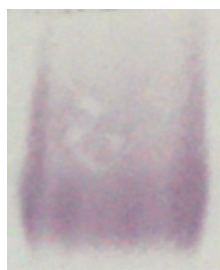

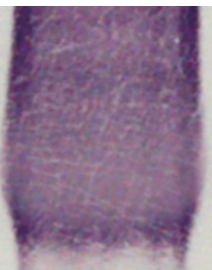

3

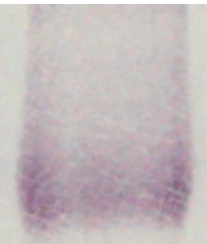

4

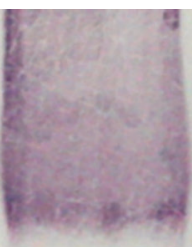

5

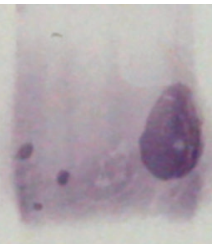

6

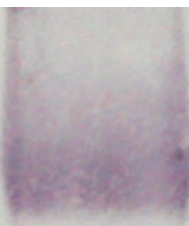

7

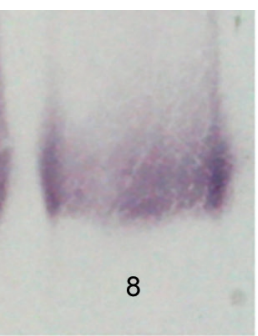

Fig. 3: Western blot gels exposed to anti-MG2 to determine the interactions between the MG2 protein and titanium disks, after salivary acquired pellicle formation. Lane 1 to Lane 8 means: 1-Supernatant SP; 2-Adsorbed SP; 3-Supernatant A; 4-Adsorbed A; 5-Supernatant SB-A; 6-Adsorbed SB-A; 7-Supernatant SB-A-NF; 8-Adsorbed SB-A-NF

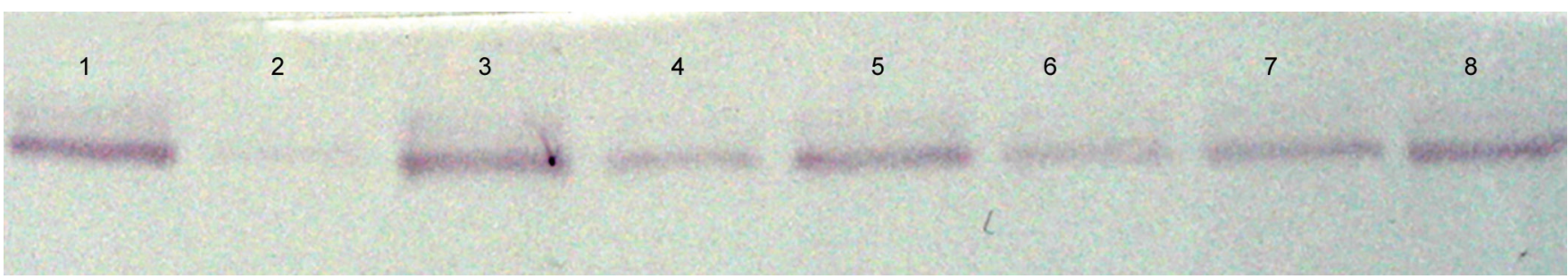

Fig. 4: Western blot gels exposed to antilactoferrin to determine the interactions between the lactoferrin protein and titanium disks, after salivary acquired pellicle formation. Lane 1 to 8 means: 1-Supernatant SP; 2-Adsorbed SP; 3-Supernatant A; 4-Adsorbed A; 5-Supernatant SB-A; 6-Adsorbed SB-A; 7-Supernatant SB-A-NF; 8-Adsorbed SB-A-NF

however, those components are still a substrate for biofilm development. ${ }^{20,21,24}$ Although the surface roughness has been recently reported as a minor importance to biofilm development, ${ }^{11,18}$ this information is still contradictory. ${ }^{12}$ Furthermore, other factors such surface free energy and the improvement of surface area may contribute to major biofilm accumulation. ${ }^{11,12,18-21}$ Considering this, effective hygiene methods must be employed continuously, in order to avoid biofilm accumulation and infections that might result in a fail of titanium placement.

\section{CONCLUSION}

The roughing of titanium surface by spot-blasting plus acid treatments etching (SB-A and (SB-A-NF) contribute to higher interaction with salivary proteins, such as MG2 and lactoferrin. Since rougher surfaces can favor microbial proliferation, caution must be taken to keep these surfaces intra-orally, sub or supra-gingivally. The titanium roughing has been used to stimulate bone marrow cells attachment, while soften surfaces are 
preferable to be in contact with gingival tissues and to prevent biofilm development.

\section{ACKNOWLEDGMENT}

This study was supported by FAPEMIG (Fundação de Amparo à Pesquisa do Estado de Minas Gerais), under grant number 261-08.

\section{REFERENCES}

1. Thull R. Physicochemical principles of tissue material interactions. Biomol Engin 2002;19:43-50.

2. Naganagowda GA, Gururaja TL, Satyanarayana J, Levine MJ. NMR analysis of human salivary mucin (MUC7) derived O-linked model glycopeptides: comparison of structural features and carbohydrate-peptide interactions. J Pept Res 1999;54:290-310.

3. Liu B, Rayment SA, Gyurko C, Oppenheim FG, Offner GD, Troxler RF. The recombinant N-terminal region of human salivary mucin MG2 (MUC7) contains a binding domain for oral Streptococci and exhibits candidacidal activity. Biochem J 2000;345:557-564.

4. Liu B, Rayment S, Oppenheim FG, Troxler RF. Isolation of human salivary mucin MG2 by a novel method and characterization of its interactions with oral bacteria. Arch Biochem Biophys 1999;364:286-293.

5. Groenink J, Ligtenberg AJ, Veerman EC, Bolscher JG, Nieuw Amerongen AV. Interaction of the salivary low-molecularweight mucin (MG2) with Actinobacillus actinomycetemcomitans. Antonie Van Leeuwenhoek 1996; 70:79-87.

6. Soares RV, Siqueira CC, Bruno LS, Oppenheim FG, Offner GD, Troxler RF. MG2 and lactoferrin form a heterotypic complex in salivary secretions. J Dental Res 2003;82:1-5.

7. Soares RV, Lin T, Siqueira CC, Bruno LS, Li X, Oppenheim FG, Offner G, Troxler RF. Salivary micelles: identification of complexes containing MG2, sIgA, lactoferrin, amylase, glycosylated proline-rich protein and lysozyme. Arch Oral Biol 2004;49:337-343.

8. Weinberg ED. Huma lactoferrin: a novel therapeutic with broad spectrum potential. J Pharm Pharmacol 2001;53: 1303-1310.

9. Apse P, Ellen RP, Overall CM, Zarb GA. Microbiota and crevicular fluid collagenase activity in the osseointegrated dental implant sulcus: a comparison of sites in edentulous and partially edentulous patients. J Periodontal Res 1989; 24:96-105.

10. Edgerton M, Lo SE, Scannapieco FA. Experimental salivary pellicle formed on titanium surfaces mediate adhesion of Streptococci. Int J Oral Maxilofac Implants 1996;11:443-449.
11. Lima EM, Koo H, Vacca Smith AM, Rosalen PL, Del Bel Cury AA. Adsorption of salivary and serum proteins, and bacterial adherence on titanium and zirconia ceramic surfaces. Clin Oral Implants Res 2008;19:780-785.

12. Dorkhan M, Chávez de Paz LE, Skepö M, Svensäter G, Davies JR. Effects of saliva or serum coating on adherence of Streptococcus oralis strains to titanium. Microbiology 2012; 158:390-397.

13. Wennerberg A, Albrektsson T. Effects of titanium surface topography on bone integration: a systematic review. Clin Oral Implants Res 2009;20:172-184.

14. Wennerberg A, Albrektsson T. On implant surfaces: a review of current knowledge and opinions. Int J Oral Maxillofac Implants 2010;25:63-74.

15. Colombo JS, Satoshi S, Okazaki J, Crean SJ, Sloan AJ, Waddington RJ. In vivo monitoring of the bone healing process around different titanium alloy implant surfaces placed into fresh extraction sockets. J Dent 2012;40:338-346.

16. Rosa MB, Albrektsson T, Francischone CE, Schwartz Filho $\mathrm{HO}$, Wennerberg A. The influence of surface treatment on the implant roughness pattern. J Appl Oral Sci 2012;20:550-555.

17. Rupp F, Scheideler L, Olshanska N, de Wild M, Wieland M, Geis-Gerstorfer J. Enhancing surface free energy and hydrophilicity through chemical modification of micro-structured titanium implant surfaces. J Biomed Mater Res A 2006;76: 323-334.

18. Al-Radha AS, Dymock D, Younes C, O'Sullivan D. Surface properties of titanium and zirconia dental implant materials and their effect on bacterial adhesion. J Dent 2012;40:146-153.

19. Yoshinari M, Oda Y, Kato T, Okuda K, Hirayama A. Influence of surface modifications to titanium on oral bacterial adhesion in vitro. J Biomed Mater Res 2000;52:388-394.

20. Quirynen M, Bollen CM. The influence of surface roughness and surface-free energy on supra- and subgingival plaque formation in man: a review of the literature. J Clin Periodontol 1995;22:1-14.

21. Quirynen M, Bollen CM, Papaioannou W, Van Eldere J, van Steenberghe D. The influence of titanium abutment surface roughness on plaque accumulation and gingivitis: short-term observations. Int J Oral Maxillofac Implants 1996;11:169-178.

22. Arneberg P. Quantitative determination of protein in saliva: a comparison of analytical methods. Scand J Dent Res 1971;79: 60-64.

23. Edgerton M, Scannapieco FA, Reddy MS, Levine MJ. Human submandibular-sublingual saliva promotes adhesion of Candida albicans to polymethylmethacrylate. Infect Immun 1993;61:2644-2652.

24. Li J, Hirota K, Goto T, Yumoto H, Miyake Y, Ichikawa T. Biofilm formation of Candida albicans on implant overdenture materials and its removal. J Dent 2012;40:686-692. 